\title{
ACADEMIC NURSE LEADERS' INTERPRETATION OF CONCEPTS AND PRIORITIES RELATED TO THE EXAMINATION OF SCIENTIFIC SHORT PAPERS, DISSERTATIONS AND THESES - PART 2
}

\author{
H. Brink
}

\section{KINDS OF EVALUATION \\ INSTRUMENTS CONSIDERED APPROPRIATE BY PANEL MEMBERS}

During the first round of the study panel members were asked to comment on the kinds of evaluation instruments they considered appropriate. The responses did not indicate clearly their preferences except that no one was in favour of a detailed evaluation instrument which indicated weights for each criterion. All participating members of the final round (6) were in favour of a broad instrument without weighting but one respondent indicated that it should not be so broad to become meaningless. All of them were in favour of a rating scale for all of the criteria. Five respondents commented that, unlike other evaluation instruments, such a scale focuses attention on essential characteristics of a research study but should include a section for comments. One respondent indicated that a rating scale for all criteria would be suitable for both qualitative and quantitative research. Five respondents claimed that separate evaluation instruments would be necessary for qualitative and quantitative research and one respondent recommended an instrument which indicated a combined weight for criteria plus a mark to take into account the variability of research studies. From these responses it appears that a preferred evaluation instrument would consist of broadly structured items rated on a scale with provision for commentary. The desirability of two evaluation forms, one for quantitative and the other for qualitative research still needs to be clarified. In the literature, different schools of thought are represented. Some qualitative researchers maintain that the standards by which quantitative studies are judged are quite inappropriate to qualitative studies (Agar 1986, Guba 1981, Kirk \& Miller 1986). Others maintain that the usual standards of good science should be retained but require redefinition in order to fit the realities of qualitative research and the complexities of social phenomena that we seek to understand (Corbin \& Strauss 1990, Strauss \& Corbin 1990). In their textbook on nursing research, Roberts and Burke (1989: 63-76) have included guidelines for evaluating nursing research reports for both quantitative and qualitative research and the possibility of adapting this for use could be investigated.

\section{INTERPRETATION OF COMMONLY USED EVALUATION CRITERIA}

A random list of general evaluation criteria, obtained from the guidelines to examiners from several universities were included in the first round questionnaire.

Respondents' interpretations of each of the given criteria are presented, followed by suggested deletions and additions to the basic criteria.

\section{Clarity of presentation}

Eight of the nine panel members participating in the second round considered this criterion important. A variety of rather vague interpretations were received from them as indicated by the following examples:

"Overall structured outline; study is set out in prescribed manner; problem is explicitly stated; purpose hypothesis and problem are clearly stated; simple and attractive style, good sentence construction and command of grammar, clear unambiguous statements".

The last two responses were each selected by one participant member of the final round as being the most appropriate explanation of clarity. The other four members selected the following long and more detailed response:

i Writing style simple, concise, precise (avoid long convoluted sentences).

ii The parts of the research report should be clearly identified.

iii Each major concept, construct and relationship should be explicitly identified and clearly defmed.

iv Key terms in the report should be defined.

$v$ Terms which have been defmed should be used consistently throughout.

iv Steps used should be clearly identified.

vii Scope of the problem and the data should be delimited.

viii The relationship of the beginning, middle and end of the research report should be clear. At end research should show how results fit back. (There should be a conceptual fit).

This last-listed response seems consistent with descriptions in nursing research textbooks (Polit \& Hungler 1991, Lo Biondo-Wood \& Harber 1990, Roberts \& Burke 1989, Woods \& 
Catanzaro 1988). Although these writers do not define explicitly or describe clarity of presentation - they refer to it throughout their discussions of a critique of a research report. Phillips (1986: 101-103 and 353) specifically refers to clarity of expression as one of the four overall criteria for evaluating any research report. She identifies the eight areas listed above and discusses them in some detail. Chinn \& Kramer (1991: 129-133) categorise 'clarity' as one of five critical reflection questions for examining a theory. For these writers 'clarity' in general refers to how well the theory can be understood and how consistently the ideas are conceptualised. In addressing 'clarity' one has to consider semantic clarity, semantic consistency, structural clarity and structural consistency.

\section{LOGICAL PROGRESSION OF IDEAS AND ARGUMENTS AND} ABILITY TO SUSTAIN ARGUMENTS

All nine respondents participating in the first round considered this criterion important enough to be included. Explanations or interpretations of it by panel members were more or less consistent. The following explanation was selected as the most suitable by all nine panel members who participated in the second round and all six participants of the third round.

\begin{abstract}
"This means systematic development or building up of an argument/analysis/ explanation. It is the natural flow of continuous thought where one idea leads or links up with the next. This makes for cohesion in a text so that one paragraph leads to the next in such a way that the whole text, no matter how long, can be readily understood and easily summarised. Ideas are so welded together that subsequent sentences have a cumulative effect on facts obtained in an earlier or key sentence".
\end{abstract}

When comparing this explanation with those in the literature, it appears that the emphasis here was on logical progression of ideas to the neglect of argument unless ideas and arguments are considered as synonyms. Phillips (1986: 103) states that the researcher has responsibility of presenting his arguments in a logical manner that explicitly reveals how each facet of the project is interrelated with the other facets. Vorster (1992: 94) maintains that the goal of presenting a coherent argument is reached when there is a connection between the problem being solved, the methods being applied, the assumptions on which the problems and methods are based and the research results which are reached.

\section{EXPLICIT RATIONALE}

This criteria too, was considered important for inclusion by all nine members who participated in the first round. Respondents were unanimous in their explanation of the term which follows - "The reader should be provided with an explicitly stated reason for every major decision in the research report". This meaning is consistent with the meaning found in nursing research textbooks previously cited but does not provide criteria for judging the adequacy of the rationale provided. According to Phillips (1986: 105) the chief criterion for judging the adequacy of the rationale provided is whether the rationale is explicit, understandable and defendable.

\section{DOCUMENTATION FROM THE LITERATURE}

This criterion was considered important for inclusion by eight of the nine participating members. One member considered it unimportant. Various explanations of the term were given and members were not unanimous as to what the term actually meant. Explanations were non-specific and vague and to a certain degree confusing as indicated in the examples listed below. The first and second listed examples were each selected by two panel members, while the third and fourth ones each were selected by one member.

\section{(1) This is evidence of the extent or amount of reading that proceeded and accompanied the compilation of the research report.}

It is the use of a variety of literature sources to gain other people's viewpoints to show both sides of an argument and to anchor or support one's standpoint. Acknowledgement of sources after direct or indirect quotations is made through foot notes, citations and references, using the recognised methods. Documen-tation can either be extensive, reasonable, scanty or absent.

\section{(2) The researcher should provide evidence}

$i$ that the current project is related to other work in the field,

ii how the current research is similar to other work in the field,

iii how the current research is different from other word in the field.

If there was very little literature available in the area of interest, evidence that research from related fields was explored should be provided.

(3) The researcher should provide

- that there is a balance between primary and secondary sources;

- that there is a balance between opinion articles and empirical work;

- that the literature has been critically analysed and evaluated.

(4) The candidate substantiates the problem from the literature.

A common factor in all these definitions is the provision of evidence. This is consistent with the meaning of documentation as defined in dictionaries, namely to support by evidence or provide with document and evidence. None of these definitions indicated criteria to evaluate the evidence and also differ with regard to the nature of the evidence. It therefore can be assumed that there would not be consistency in the examination of this point. Nursing research textbooks as a rule do not devote a separate heading to this and it was difficult to establish agreement or otherwise with this point in the literature. Phillips (1986: 105 and 148) includes documentation as one of the four basic research evaluation criteria. She makes a distinction between the substantive literature review and references to the literature which should appear throughout the research report to substantiate various features of the design, methodology and statistical techniques. Students also are expected to provide evidence for all decisions taken. Although they can do this through logical argumentation, a commoner way is by substantiation with literature. It therefore would appear that these references should fall under the term 'documentation of literature'. The question remains about what the examiner should evaluate with regard to this aspect? Top priorities identified by Wilson (1989: 182) are adequacy and relevance. Do these selected references pertain logically to the subject under study and the methodology used? Do they clearly support theoretical arguments being made and represent the most powerful studies done in the field? Are they reliable? Are they recent or if old, are they classics? Are they balanced? Are they from primary sources or secondary sources? Are they recorded consistently throughout? Are they identifiable and are they all listed in the list of sources at the end? 


\section{CRITICAL ABILITY}

There was unanimous agreement among all nine participating panel members that critical ability was an important aspect to be evaluated. One respondent however, considered it an advanced skill which she would not expect in a scientific short paper. In the second round five of the nine panel members agreed with this statement and in the final round, two of the six respondents agreed with it. In view of the fact that critical ability is considered one of the crucial characteristics of both scientists and academics (Polgar \& Thomas 1988: 9, Van Vuuren 1993: 23) and a purpose of the scientific short paper is to demonstrate that the student is conversant with the methods of science, the scientific community at large would expect it to be reflected in a scientific short paper.

Participating members were divided in their opinion on responses which most appropriately reflected the meaning of critical ability. Two responses were selected, each one by three members. These responses are presented below:

(1) This consists of making a critical assessment, the ability to evaluate, judge, compare and to identify the essentials of an argument or viewpoint. It means weighing strengths of a statement or viewpoint against its weakness, validity against invalidity primary status against secondary status and therefore, deducing acceptability or best use of the matter in question.

(2) This consists of making critical assessments, and the candidate must show that he/she is able to question and analyse other findings, ideas and concepts and draw his/her own conclusions.

"Scepticism", (the notion that any proposition or statement, even when made by great authorities, is open to doubt and analysis) is regarded a basic element of the scientific method (Polgar \& Thomas 1988: 9) and therefore of critical ability (Van Vuuren 1993: 24). A sceptic questions. Critical ability therefore requires the scientist to question. This element is included in the second listed response but not in the first one. Critical ability also includes objectivity, an open mind and flexibility and the ability to express a reasoned opinion (Van Vuuren 1993: 24). In addition to these points and the points in the responses listed above, critical ability can be assessed by asking the following questions:
- Is the reasoning unambiguous?

- Are all facts presented impartially and in a balanced manner?

- Is the candidate able to distinguish essentials from non-essentials?

- Is the candidate consistent in his argumentation? (Landman 1993:79).

Based on the information from the literature, it is suggested that the two responses given by participants are combined and reformulated.

\section{SCHOLARSHIP AND \\ ACQUAINTANCE WITH RESEARCH METHODS}

All nine participating members of the first round agreed that this aspect should be evaluated but one member suggested that the term scholarship be dropped and be explored separately. In the second round three members agreed with this point but during the final round only one person selected this option as suitable. The remaining five members all selected the only other response given. Both responses are presented below:

(1) (I would prefer the word "scholarship" to be dropped from this heading since it is one of those vague terms which could have been explored under 2.) I would expect a clear research design here, which makes it clear how every research objective is going to be addressed. The population should be defined and the sampling technique described fully enough to be replicated. The data collection technique must be described and any instrument information about reliability and validity has to be given (if it is a tested instrument - If not, if the researcher developed it, the process of development and theoretical rationale has to be given).

(2) It is shown by:

- use of higher intellectual abilities;

- efficient and effective use of other writers' points of view;

- discreet and appropriate use of different views, of figures of speech and even of difficult words;

- competent use of language to portray one's thoughts;

\section{- advancing of valid rationale;}

- appropriate choice and competent use of research designs, tools, sample and methods of data analysis;
- reasonable handling of ethical implications;

- drawing logical conclusions flowing from findings and reflecting attainment of pre-determined objectives;

\section{- competence in presenting a research report.}

Most research textbooks refer to scholarly research and scholarly writings but do not clarify what this comprises. It may be a good idea to clarify these terms separately, and to specify subcriteria.

Armiger (1974: 162-163), writing about scholarship in nursing, identified several scholarly characteristics. "Scholarliness signifies a willingness to stand alone in the support of one's convictions. Scholarliness is persistence and dedication, flexibility, a willingness to weigh all sides of an issue, and respect for divergent opinions. It is the pursuit of excellence and absolute accuracy, not only in scholarly research but in all aspects of the scholar's life. Unconditional integrity and intellectual honesty and a high level of personal, academic and professional standards also prevails among genuine scholars. A scholar demonstrates proficiency, mastery of systematised knowledge and excellence in performance. A scholar exemplifies creativity and a high level of self-discipline, not only in pursuit of fundamental questions but also in encouraging their exploration by others". Meleis (1985: 300) states "scholarliness combines theory, research, philosophy and practice". Although there is overlapping with several other criteria, these characteristics should provide good indication of that for which the examiner looks.

Neither of the two responses are explicit enough to clarify an 'adequate research method'. For example, members stated the population should be defined and the sampling technique described. This may have been done inappropriately. Would it not be more meaningful to take each step of the research method and identify aspects which would indicate its quality, as Polit \& Hungler (1991: 584-596) or Roberts \& Burke (1989: 63-76) have done in their textbooks on nursing research.

\section{KNOWLEDGE OF RELEVANT LITERATURE}

Seven of the nine panel members participating in the first round regarded this criterion as sufficiently important for inclusion in an evaluation instrument. All six participating panel members of the final round unanimously agreed upon the response presented below as most 
appropriately reflecting their interpretation:

(1) The review of the literature should be comprehensive. All the cited references should be really relevant to the problem under investigation, but all concepts should be adequately covered.

(2) Most current literature available on the area of interest as well as classical studies should be included.

(3) There should not be an overdependency on secondary sources when primary sources could have been obtained.

(4) Empirical work should receive greater emphasis than opinion articles.

(5) Literature reviewed should appraise critically and compare the contributions of key studies. Literature review should conclude with the implications for the problem under investigation.

The aspects included here are found in most nursing research textbooks as well as other literature on theses and dissertations (Bodenstein 1993, Landman 1993). Phillips (1986: 149) regards the following aspects as important - the literature review should be logically developed, organised into major concepts and provide a clear statement of how the study fits into a broader knowledge base and of the strengths and gaps in the current knowledge base. Roberts \& Burke (1989: 68) and Polit \& Hungler (1991: 587) point to the importance of including studies which both support and conflict with researcher's prediction. The latter suggest that the review should conclude with a brief synopsis of the state of the art of the literature on the topic.

\section{TECHNICAL COMPETENCE}

Three of the nine panel members participating in the first round did not consider technical competence sufficiently important to be included as an evaluation criterion. This is contrary to expectations gleaned from the literature (Landman 1993, Bodenstein 1993, Arrangies \& Du Plessis 1992, Vorster 1992, Polit \& Hungler 1991) and of universities but there was unanimity among panel members who participated in the second and final rounds regarding the most appropriate explanation of this term. The explanation is reflected below:
This is manifest through the proper format, neat, orderty and systematic layout of the report.

\section{For instance:}

- orderly and systematic organisation and arrangement of the report;

- number and types of headings and subheadings to conform to a particular, accepted pattem;

- correct numbering of pages using Roman figures for preliminary pages and Arabic numerals for main body, numbers to be in the same position in all pages (eg at centre or comer);

- correct and consistent numbering of items, tables, headings and subheadings;

- consistent pattern of spacing, indenting, underlining, margins (top, bottom and sides);

- appealing style, which includes: - correct spelling and sentence construction;

- appropriate use of capital letters, abbreviations, punctuation marks;

- avoiding use of 1st person pronoun;

- effective use of examples, figures, diagrams, graphs and tables.

In the literature a number of additional points are included, namely title page, foreword, table of content, summary or abstract, bibliography, appendix, printing and binding and readability (Bodenstein 1993, Dreyer 1981, Landman 1993, Vorster 1992).

\section{ABILITY TO DIFFERENTIATE BETWEEN ESSENTIAL AND RELEVANT VS SECONDARY IMPORTANCE AND IRRELEVANT}

Seven of the panel members participating in the first round considered this term sufficiently important to be included as an evaluation criterion. However, when required to explain what they thought should be included under this term, two of the nine members participating in the second round indicated that it belongs under the criteria 'logical progression of ideas and arguments' and 'ability to sustain argument'. Six members of the second round and all members participating in the final round grouped it under 'critical ability'. Yet, when referring back to 'critical ability' it will be noted that no one had included it in their explanation of the term. It is reflected as a characteristic of 'critical ability' in the literature.
VALIDITY OF CONCLUSIONS IN LIGHT OF ARGUMENT

Two of the nine panel members participating in the first round did not regard this criterion to be sufficiently important to be included as an evaluation criterion; however, when required to explain what should be included, there was unanimity among all nine members participating in the second round and all six in the final round regarding the most appropriate explanation of the term. The explanation given is reflected below:

Conclusions must be totally supported by findings, taking into consideration the population and the limitations of the study.

The candidate should not repeat the results here, but draw a few conclusions based on the results.

Conclusion based on results need not necessarily be valid. If the findings are invalid, conclusions will also be invalid. Several writers of nursing research textbooks point out that the critic needs to determine whether conclusions are justified by the procedures used and the data obtained. Were the procedures and methods appropriate to the purpose, were they adequate and did they ensure valid and reliable data? Was the analysis plausible? Could there be alternative explanations for findings? Were the research decisions made by the researcher logical? Is each result interpreted in light of findings from similar results? (Polit \& Hungler 1991, Phillips 1986, Woods and Cantanzaro 1988). Based on the literature it is suggested that this point be reformulated and made more explicit.

\section{CHANGES TO CRITERIA AS SUGGESTED BY PANEL MEMBERS}

\section{Deletions from list of basic criteria}

Several panel members in both the second and third rounds suggested deletions from the list of basic criteria reflected in Table 1.

It is difficult to identify the rationale underlying these suggestions as none of the panel members had previously listed these criteria as components of those with which they are now associated, neither is such evidence reflected in the literature pertaining to these criteria, with the exception of ability to differentiate between essential vs secondary importance as part of critical ability. This has been referred to previously. An indepth probing and analysis of these concepts is therefore indicated. 
Table 1

Suggested deletions from list of besic criterla, reasons and number of participants in agreement.

\begin{tabular}{|c|c|c|c|}
\hline \multirow{2}{*}{ Crtteria to be deleted } & \multirow{2}{*}{ Reeson } & \multicolumn{2}{|c|}{$\begin{array}{l}\text { Number of } \\
\text { partlcipents who } \\
\text { agreed }\end{array}$} \\
\hline & & $\begin{array}{c}\text { Round } 2 \\
n=9\end{array}$ & $\begin{array}{c}\text { Round } 3 \\
n=9\end{array}$ \\
\hline Knowledge of relevant literature. & $\begin{array}{l}\text { Is part of logical progression of } \\
\text { ideas etc and documentation } \\
\text { from the literature. }\end{array}$ & 6 & 6 \\
\hline $\begin{array}{l}\text { Ability to differentiate between } \\
\text { essential and relevant vs of } \\
\text { secondary importance and } \\
\text { irrelevance. }\end{array}$ & $\begin{array}{l}\text { Is part of critical ability. } \\
\text { Is part of technical competence. }\end{array}$ & $\begin{array}{l}5 \\
0\end{array}$ & 5 \\
\hline Critical ability. & $\begin{array}{l}\text { Is part of logical progression of } \\
\text { ideas etc. }\end{array}$ & 6 & 5 \\
\hline $\begin{array}{l}\text { Validity of conclusions in light of } \\
\text { argument and explicit rationale. }\end{array}$ & $\begin{array}{l}\text { is part of scholarship and } \\
\text { acquaintance of research } \\
\text { methods explicit rationale is part } \\
\text { of logical progression of ideas, } \\
\text { etc. }\end{array}$ & $\begin{array}{l}1 \\
4\end{array}$ & 2 \\
\hline
\end{tabular}

A strong case can be made for inclusion of one of the criteria suggested in Table 2. Topicality of theme is a criterion included in the literature and by many universities in their guidelines (Landman 1993) and therefore requires consideration. The term was omitted inadvertently from the questionnaire but certainly should be included in an evaluation instrument. It is surprising though that only three panel members are in agreement with this.

It seems redundant to include "objectivity" and "honesty", "insight into field of study" and "interpretation of knowledge/facts" as separate basic criteria. As previously mentioned "objectivity" is a component of critical ability, "honesty" is characteristic of scholarship, "insight into field" is implied under knowledge of relevant literature while interpretation of knowledge/facts could stand under either critical ability or acquantance with research methods (see discussions under these criteria).

It is difficult to comment on the fifth, sixth and seventh listed suggestions as it is not clear to what respondents actually were referring. The suggestions thus are not regarded sufficiently explicit to be included as criteria.

The last two suggestions listed are not basic criteria but merit consideration. The researcher had expected panel members to provide components of criteria in their explanation of what they understand by these criteria. Unfortunately, with a few exceptions, this did not materialise and there appears to

Table 2

Suggested additions to list of basic criteria and number of participants in agreement.

\begin{tabular}{|c|c|c|}
\hline \multirow{2}{*}{ Suggeated additional criteria } & \multicolumn{2}{|c|}{$\begin{array}{l}\text { Number of paricipants } \\
\text { in agreement }\end{array}$} \\
\hline & $\begin{array}{l}\text { Firet } \\
\text { Round }\end{array}$ & $\begin{array}{l}\text { Socond } \\
\text { Round }\end{array}$ \\
\hline Objectivity and honesty & 9 & 5 \\
\hline Insight into field of study & 4 & 4 \\
\hline Interpretation of knowledge/facts & 5 & 5 \\
\hline Theme must be timely, topical and of current interest & 3 & 3 \\
\hline Topic must be presented and treated in original format & $\begin{array}{r}3 \\
\text { (6 queried } \\
\text { this } \\
\text { statement) }\end{array}$ & 1 \\
\hline $\begin{array}{l}\text { Research must be first-hand and based on scientifically } \\
\text { acceptable principles }\end{array}$ & 3 & 1 \\
\hline Research report must form a complete whole & 4 & 3 \\
\hline Components of criteria should be included & 3 & 5 \\
\hline Criteria should be re-arranged and marked differently (a model & 7 & 5 \\
\hline
\end{tabular}

be a real need either to include components, or questions to be answered on each criteria as guidance for examines. Polit \& Hungler (1991: 585-595) show use of this last suggestion.

The list of basic criteria given in the questionnaire was a random list, somewhat haphazard and was not intended to simulate the format of an evaluation instrument. It stands to reason therefore that these criteria should be rearranged as suggested, though it is not clear what respondents meant by marking them differently. The model provided included the following:

a Introduction.

Clarity of problem presentation (problem is added).

b Literature survey.

c Research methods.

\section{d Conclusions.}

f General.

Logical progression of ideas and arguments, and ability to sustain arguments.

Explicit rationale.

Technical competence.

As reflected in Table 2 the majority of panel members were in agreement with this model. Only one member disagreed and provided the following comments:

I would disagree that attention to clarity is reserved for only the problem, or that only the clarity of problem presentation is focused on in the introduction, what about research questions and/or hypothesis; assumptions; operational and theoretical definitions, theoretical framework and so on, and what about the ethical aspects. Furthermore, because this evaluation instrument is intended for postgraduate projects, academic considerations dictated by the universities must be included. However, the suggested model does not provide for criteria such as original research, contribution to knowledge, ability to undertake independent research, critical ability and scholarliness.

Although this is a minority opinion it deserves merit and should be reconsidered by other panel members.

Several models are presented in the literature. Phillips (1986) divides hers into general criteria and content criteria. She maintains that there are four overall 
basic criteria that a critic can reasonably expect from every final report of a research study, regardless of the type of question, the theoretical position, the type of methodology or the substantive area of inquiry. These four criteria are:

(1) clarity of presentation

(2) logical progression of arguments

(3) explicit rationale and

(4) documentation from the literature (page 101)

If the report meets these four basic criteria the researcher proceeds to the more complex task of evaluating the research part by part. She sets out twelve areas for consideration (p 106).

Polit \& Hungler (1991) identify five important dimensions that should be considered in a critical evaluation of a research study. Under each dimension several specific aspects for consideration are listed. The examination should reflect a thoughtful, objective and balanced consideration of each dimension. They present guidelines for evaluating the various aspects, start off with general guidelines to be considered and then give guidelines for fifteen aspects (pages 585-595).

Bodenstein (1993) in his suggested model, presents eight major aspects, each one with specific components, and sometimes subcomponents. These eight areas are:

(1) The research plan which includes topic, problem statement and formulation, aim and hypotheses (where applicable) each with several subcriteria.

(2) Research methods and procedures.

(3) Scientificality, which includes theoretical grounding, conceptualisation, independence, logical progression of arguments, systematising, critical ability, clarification of philosophical views, quality of argumentation, ability to make scientific interpretation and report in a scientific manner.

(4) Content.

(5) Literature review and documentation.

(6) Language, style and technical aspects.

(7) Findings and recommendations.
(8) Contribution to knowledge under which he includes original research and ability to do independent research - all these models are very useful and provide excellent directions to an examiner.

\section{CRITERIA FOR PASSING/FAILING/ MAJOR REVISION/DISTINCTION}

Panel members had been requested to explain when they would expect a dissertation or thesis to be passworthy, worthy of distinction, requiring major revision or doomed for failure. Responses are reflected in Tables 3 to 6 .

Although both responses appear to focus on the same aspects, the first one is more explicit; neither provides a completely balanced perspective. Furthermore, neither of the two responses differentiates between dissertations and theses and therefore it is not clear whether members use identical criteria in considering the passworthiness of the different documents. If this is the case it is not consistent with university requirements, and especially does not appear to be fair on the master's student.

As reflected, all six panel members participating in the fmal round were unanimous in agreeing with the first statement but the question arises as to what decision will be taken if there are major faults in one of the main aspects? Will the report be accepted?

A careful analysis of all the criteria listed in Tables 3 to 6 raises the question whether any of these suggested criteria are sufficiently explicit and specific to provide direction for objective unbiased fair decisions. Particular problems arise with determining what is good or what is poor or what is reasonably well? Would it be possible to have no technical skill or have totally useless data? Would these criteria apply equally to both master's and doctoral studies? Further clarification is indicated.

There is a paucity of literature on criteria relating to passworthy, distinction, doomed to failure. Only one article was found in which brief reference was made to these aspects. Perreira (1984: 35) writing on the master's degree in university department's of English expressed the view that a passworthy dissertation would have earned a plus on each of the major criteria or aspects that are evaluated, though one might find fault with certain aspects of each. A "distinction effort" should not only satisfy on all the counts, but exhibit to a heightened degree, the qualities, or the greater part of them, subsumed under each heading. One would reject or (depending on the nature and extent of the fault) refer back for extensive revision a dissertation which failed to satisfy on one or more of the major counts.

Perreira's suggestion would make it essential to have a well-structured evaluation instrument which covers all major aspects, combined with a rating scale for each item under each aspect as a guideline. Each item then would be rated and marks allocated according to ratings. If there were minor faults under certain aspects, it still could be termed passworthy, provided the candidate made minor alterations. This would bring about a more balanced, objective, fair and just examination and rating system.

\section{DISCUSSION}

The principle of communality is accepted universally and supported by the scientific community as one of the key principles in science. It is concerned with dialogue and exchange of one's work with

\begin{tabular}{|c|c|c|}
\hline \multicolumn{3}{|c|}{$\begin{array}{l}\text { Table } 3 \\
\begin{array}{l}\text { Criteria suggested by panel members for passing a dissertation/thesis } \\
\text { and number of agreements with each. }\end{array}\end{array}$} \\
\hline \multirow[b]{2}{*}{ Criterla suggested by panel members } & \multicolumn{2}{|c|}{ Number of agreements } \\
\hline & $\begin{array}{l}\mathbf{N}=9 \\
\text { Second } \\
\text { Round }\end{array}$ & $\begin{array}{l}N=6 \\
\text { Find } \\
\text { Round }\end{array}$ \\
\hline $\begin{array}{l}\text { The candidate demonstrated an ability to handle research data } \\
\text { in a scientific manner, answers the research questions, draws } \\
\text { valid conclusions from the findings and shows evidence of up to } \\
\text { date literature which has been used to either refute or confirm } \\
\text { findings. Mistakes do not affect the findings. }\end{array}$ & 5 & 4 \\
\hline $\begin{array}{l}\text { If the candidate did what she set out to do in terms of answering } \\
\text { the research question in a valid and reliable manner. Where she } \\
\text { made mistakes, it did not materially affect the validity of the } \\
\text { research answer to the question. }\end{array}$ & 4 & 2 \\
\hline
\end{tabular}


Table 4

Crtteria identfied by panel members for awarding distinctions and number of agreements with each.

\begin{tabular}{|l|r|r|}
\hline \multicolumn{1}{|c|}{ Crtteria suggested by panel members } & \multicolumn{2}{|c|}{ Number of agreements } \\
\cline { 2 - 3 } & $\begin{array}{r}\text { N=9 } \\
\text { Second } \\
\text { Round }\end{array}$ & $\begin{array}{c}\text { Final } \\
\text { round }\end{array}$ \\
\hline $\begin{array}{l}\text { Every component is handled almost faultlessly, a complex } \\
\text { question/approach is handled expertly, or creative methodology } \\
\text { is developed. }\end{array}$ & 6 & 5 \\
$\begin{array}{l}\text { If it meets all criteria reasonably well and in addition, the student } \\
\text { distinguishes herself in } \\
\text { - scholarship } \\
\text { originality } \\
\text { both of which I think are critical variables. }\end{array}$ & $1+$ \\
\hline
\end{tabular}

+ A further comment was made by this member, namely that no research is ever taulliess, overy research has some flaws, hence the first criterion would be unattainable.

\begin{tabular}{|l|r|r|}
\hline \multicolumn{3}{|c|}{$\begin{array}{c}\text { Table } 5 \\
\text { Criteris identfied by panol members for "major revision" and } \\
\text { number of agreements }\end{array}$} \\
\hline \multicolumn{1}{|c|}{ Criteria suggested by panol members } & Number of agreements \\
\cline { 2 - 3 } & $\begin{array}{c}\mathbf{N}=9 \\
\text { Second } \\
\text { Round }\end{array}$ & $\begin{array}{r}\text { N=6 } \\
\text { Final } \\
\text { Round }\end{array}$ \\
\hline $\begin{array}{l}\text { If the dissertation is poor in two or three aspects that can be } \\
\text { corrected without restructing most or the whole of the report. } \\
\text { If enormous mistakes are made in the logic of the design, or in } \\
\text { any other process of the logic of the project. } \\
\text { If results are not discussed clearly, conclusion unsound. }\end{array}$ & 5 & 6 \\
\hline
\end{tabular}

\begin{tabular}{|c|c|c|}
\hline \multicolumn{3}{|c|}{$\begin{array}{l}\text { Table } 6 \\
\text { Criteria identified by panol members for failing a candidate } \\
\text { and number of agreements with each criterion. }\end{array}$} \\
\hline \multirow[t]{2}{*}{ Criteria suggested by panel members } & \multicolumn{2}{|c|}{ Number of agreements } \\
\hline & $\begin{array}{l}N=9 \\
\text { Second } \\
\text { Round }\end{array}$ & $\begin{array}{l}\mathbf{N}=6 \\
\text { Final } \\
\text { Round }\end{array}$ \\
\hline $\begin{array}{l}\text { If there is a need for extensive restructing - for example } \\
\text { - poor design } \\
\text { - poor research methodology } \\
\text { - no technical skills } \\
\text { - unethical } \\
\text { - poor literature review. }\end{array}$ & 4 & 4 \\
\hline $\begin{array}{l}\text { When the data collected is totally useless, even when the } \\
\text { research question is changed. Basically, when the change } \\
\text { proposed is so major that it means a new research project. }\end{array}$ & 2 & 1 \\
\hline $\begin{array}{l}\text { If the dissertation is poor in research skills and methods, } \\
\text { scholarship and in technical requirement and would need } \\
\text { extensive restructuring. }\end{array}$ & 3 & - \\
\hline A combination of all three the above. & - & 1 \\
\hline
\end{tabular}

others, the opportunity for competent opinion of the work, and the promise, if not fulfilment of colleagueship and collaboration (Gortner 1980: 180). When scientists pool their thoughts, ideas are clarified, errors of reasoning are uncovered and a variety of refreshing unique perspectives are provided which help to broaden the knowledge.
Bearing this principle in mind, it is regrettable that only a small proportion of the heads of nursing departments of Southern African universities responded to the invitation to share their ideas on examination of postgraduate project with their colleagues. Only nine of the eighteen invited heads or their delegates participated in the first and second rounds and only six in the final round. Two possible explanations for this can be offered. First, as far as could be established, seven of the eighteen nursing departments invited do not offer postgraduate courses. This does not preclude them from acting as examiners but the heads of these departments may have considered this exercise irrelevant for them. Secondly, to save on costs in terms of time, labour and money, the questionnaire was sent out in only one official language, namely English. Although no direct complaints were received, it may have affected the response rate.

Fortunately, the nature of the study was such that the purpose of the study, "to establish whether there is agreement among academic nurse leaders in their interpretation of aspects and criteria related to the examination of postgraduate projects" could be met without a large sample.

As reflected by the results, there is very little agreement even among the small sample on most of the aspects relating to master's and doctoral projects. A larger sample would not have made much difference to this particular finding. Even if all nonrespondents had unanimously agreed on every aspect there would still have been lack of consensus in the total group. However, whilst the purpose of the study was met, one of the secondary objectives for the Delphi Technique, namely to generate consensus on the part of the respondent group, was not met. The rounds were discontinued before consensus had been generated, because it seemed senseless to achieve this objective with so small a group. The poor response rate therefore did have some effect on the study.

The finding that many of the aspects are interpreted in different ways by examiners lends support to Burns \& Grove's statement that, although a list of criteria can serve a useful guide, it need not necessarily do so. To be effective, it requires shared meanings in the interpretation of concepts and prioritising of criteria. In general, with perhaps a few exceptions, the community of academic nurse leaders do not yet share meanings.

The findings suggest that several interpretations are based on personal opinion and feeling and not on the norms and standards suggested by the scientific community and therefore lend support to Vorster's view that "the examination tends to become a personal and subjective matter with each examiner expressing his/her own opinion about standards". 
The conclusion is drawn that to date insufficient attention has been given to the norms and standards underlying evaluation of research reports, that academic nurse leaders practice their science in relative isolation and do not invest sufficient time or effort into collegial or collaborative relationships regarding this issue.

\section{It is recommended that}

- concerted efforts be made to give more attention to the critiquing of research reports, both in formal and continuing education nursing programmes - there is a much literature available on this aspect;

- a committee of interested members be formed to compile a well-balanced, systematised explicit evaluation instrument for critiquing master's and doctoral theses according to acceptable scientific norms and standards;

- on completion of such an instrument it be presented to all nurse academics who are in possession of at least a master's degree, for their comment.

\section{REFERENCES}

AGAR, M. (1986). Speaking of ethnography. Beverley Hills: Sage.

ARMIGER B. (1974). Scholarship in nursing. Nursing Outlook 22 (no. 3): 162-163.

ARRANGIES, J. \& DU PLESSIS, S.J.P. (1992). Die eksaminering van skripsies, verhandelinge en proefskrifte. SAJHE 6 (no. 1, 1992): 31-34.

BODENSTEIN, H.C.A. (1993). Die skryf van 'n eksaminatorsverslag in Die Professor as mentor edited by P.C. van Wyk. Pretoria: Unisa.

BOTHA, E. (1992). The nature of dissertations and theses in Succeed at dissertation edited by Botha \& Engelbrecht. Halfway House: Orion.

BURNS, N. \& GROVE, S.K. (1987). The practice of nursing research. Philadelphia: Saunders.
CHINN, P.L. \& KRAMER, M. (1991). Theory and nursing. St Louis: Mosby.

CORBIN, J. \& STRAUSS, A. (1990). Grounded theory method: procedures, canons and evaluative criteria. Qualitative Sociology (13) (no. 1): 3-21.

DREYER, HJ. (1981). Master Doctor: a manual for the writing of dissertations and theses. Umlazi: Unizul.

GORTNER, S.R. (1980). Nursing science in transition. Nursing Research 29 (no. 3): 180-183.

GUBA, E. (1981). Criteria for assessing the trustworthiness of naturalistic inquiries. ETC 19: 75-91.

KIRK, J. \& MILLER, M. (1986). Reliability, validity and qualitative research. Beverley Hills C.A.: Sage.

LANDMAN, W.A. (1993). Analise van verslae van leiers, promotors en eksaminatore in Die Professor as mentor edited by P.C. van Wyk. Pretoria: Unisa.

LO BIONDO-WOOD, G. \& HABER, J. (1990). Nursing research, methods, critical appraisal and utilisation. St Louis: Mosby.

LOMBARD, H.A. (1993). Getting started in Succeed at dissertation edited by Botha \& Engelbrecht. Halfway House: Orion.

MELEES, A.I. (1985). Theoretical nursing: development and progress. Philadelphia: Lippincott.

PERREIRA, E. (1984). The master's degree in University Departments of English. Progessio 6 (no. 2): 28-36.

PHILLIPS, L.R. (1986). A clinicians guide to the critique and utilisation of nursing research. Norwalk / Con e c t i c u t : Appleton-Century-Crofts.

POLGAR, S. \& THOMAS, S. (1988). Introduction to research in the health sciences. Edinburgh: Churchill Livingstone.
POLIT, D.F. \& HUNGLER, B.P. (1991). Nursing research: principles and methods. Philadelphia: Lippincott.

ROBERTS, C.A. \& BURKE, S.O. (1989). Nursing research: a quantitative and qualitative approach. Boston: Jones and Bartlett.

STRAUSS, A. \& CORBIN, J. (1991). Basics of qualitative research. Newbury Park: Sage.

TREECE, E.W. \& TREECE, J.W. (1986). Elements of research in nursing. St Louis: Mosby.

VAN VUUREN, J.C.G.J. (1993). Die moontlike waarde van mentorskap vir die universiteit in Die Professor as mentor edited by P.C. van Wyk. Pretoria: Unisa.

VORSTER, W.S. (1992). The examination process in Succeed at dissertation edited by Botha \& Engelbrecht. Halfway House: Orion.

WILSON, H.S. (1989). Research in nursing. Menlo Park C.A.: Addison-Wesley.

WITTGENSTEIN, L. (1961). (1922). Tractatus logico-philsophicus. London: Routledge and Kegan Paul.

\section{ACKNOWLEDGEMENT}

I wish to express my sincere appreciation to SANA Head Office, in particular Mrs E Hattingh, and Mrs $H$ Geyer for their assistance with the project and to all the panel members who participated, for their time and effort. 